\title{
Evolution of Combustion-Generated Particles at Tropospheric Conditions
}

Kathleen M. Tacina and Christopher M. Heath

Glenn Research Center, Cleveland, Ohio 


\section{NASA STI Program . . . in Profile}

Since its founding, NASA has been dedicated to the advancement of aeronautics and space science. The NASA Scientific and Technical Information (STI) program plays a key part in helping NASA maintain this important role.

The NASA STI Program operates under the auspices of the Agency Chief Information Officer. It collects, organizes, provides for archiving, and disseminates NASA's STI. The NASA STI program provides access to the NASA Aeronautics and Space Database and its public interface, the NASA Technical Reports Server, thus providing one of the largest collections of aeronautical and space science STI in the world. Results are published in both non-NASA channels and by NASA in the NASA STI Report Series, which includes the following report types:

- TECHNICAL PUBLICATION. Reports of completed research or a major significant phase of research that present the results of NASA programs and include extensive data or theoretical analysis. Includes compilations of significant scientific and technical data and information deemed to be of continuing reference value. NASA counterpart of peer-reviewed formal professional papers but has less stringent limitations on manuscript length and extent of graphic presentations.

- TECHNICAL MEMORANDUM. Scientific and technical findings that are preliminary or of specialized interest, e.g., quick release reports, working papers, and bibliographies that contain minimal annotation. Does not contain extensive analysis.

- CONTRACTOR REPORT. Scientific and technical findings by NASA-sponsored contractors and grantees.
- CONFERENCE PUBLICATION. Collected papers from scientific and technical conferences, symposia, seminars, or other meetings sponsored or cosponsored by NASA.

- SPECIAL PUBLICATION. Scientific, technical, or historical information from NASA programs, projects, and missions, often concerned with subjects having substantial public interest.

- TECHNICAL TRANSLATION. Englishlanguage translations of foreign scientific and technical material pertinent to NASA's mission.

Specialized services also include creating custom thesauri, building customized databases, organizing and publishing research results.

For more information about the NASA STI program, see the following:

- Access the NASA STI program home page at http://www.sti.nasa.gov

- E-mail your question via the Internet to help@ sti.nasa.gov

- Fax your question to the NASA STI Help Desk at $443-757-5803$

- Telephone the NASA STI Help Desk at 443-757-5802

- Write to: NASA Center for AeroSpace Information (CASI) 7115 Standard Drive Hanover, MD 21076-1320 


\section{Evolution of Combustion-Generated Particles at Tropospheric Conditions}

Kathleen M. Tacina and Christopher M. Heath

Glenn Research Center, Cleveland, Ohio

Prepared for the

Turbo Expo 2010

sponsored by the American Society of Mechanical Engineers (ASME)

Glasgow, Scotland, United Kingdom, June 14-18, 2010

National Aeronautics and

Space Administration

Glenn Research Center

Cleveland, Ohio 44135 


\section{Acknowledgments}

This research was funded by NASA's Fundamental Aeronautics/ Subsonic Fixed Wing and Fundamental Aeronautics/Supersonics program.

Trade names and trademarks are used in this report for identification only. Their usage does not constitute an official endorsement, either expressed or implied, by the National Aeronautics and Space Administration.

This work was sponsored by the Fundamental Aeronautics Program at the NASA Glenn Research Center.

Level of Review: This material has been technically reviewed by technical management.

Available from

NASA Center for Aerospace Information 7115 Standard Drive

Hanover, MD 21076-1320
National Technical Information Service 5301 Shawnee Road Alexandria, VA 22312 


\title{
Evolution of Combustion-Generated Particles at Tropospheric Conditions
}

\author{
Kathleen M. Tacina and Christopher M. Heath \\ National Aeronautics and Space Administration \\ Glenn Research Center \\ Cleveland, Ohio 44135
}

\begin{abstract}
This paper describes particle evolution measurements taken in the Particulate Aerosol Laboratory (PAL). The PAL consists of a burner capable of burning jet fuel that exhausts into an altitude chamber that can simulate temperature and pressure conditions up to $13,700 \mathrm{~m}$. After presenting results from initial temperature distributions inside the chamber, particle count data measured in the altitude chamber are shown. Initial particle count data show that the sampling system can have a significant effect on the measured particle distribution: both the value of particle number concentration and the shape of the radial distribution of the particle number concentration depend on whether the measurement probe is heated or unheated.
\end{abstract}

\section{Nomenclature}

$B$ Buoyancy flux

$d_{0}$ Nozzle diameter

$d^{*}$ Equivalent source diameter, $d^{*}=d_{0} \sqrt{\frac{\rho_{0}}{\rho_{\infty}}}$

$g$ Gravitational constant

$J$ Momentum flux

$l_{c}$ Coflow length scale

$l_{M}$ Morton length scale $m$ Mass flux

$Q$ Volume flux

$R$ Richardson number

$r$ Radial coordinate

Re Reynolds number

$T$ Temperature

$u$ Velocity

$x$ Axial distance from the jet exit plane

$x_{E}$ Axial distance from the virtual origin to the jet exit plane

$\rho$ Density

$\theta$ Normalized temperature difference, $\frac{T-T_{\infty}}{T_{0}-T_{\infty}}$

$\zeta$ Particle number concentration

Subscripts

0 Nozzle exit

CL Centerline

$\infty$ Chamber 


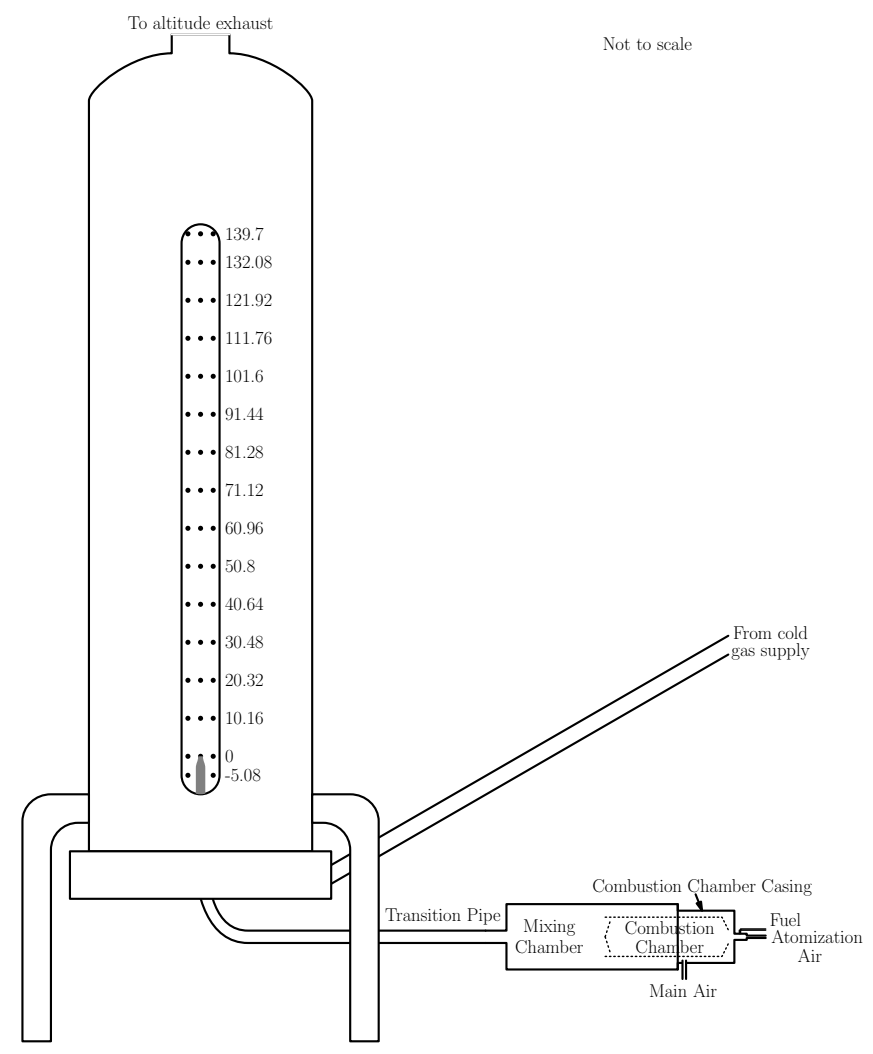

(a)

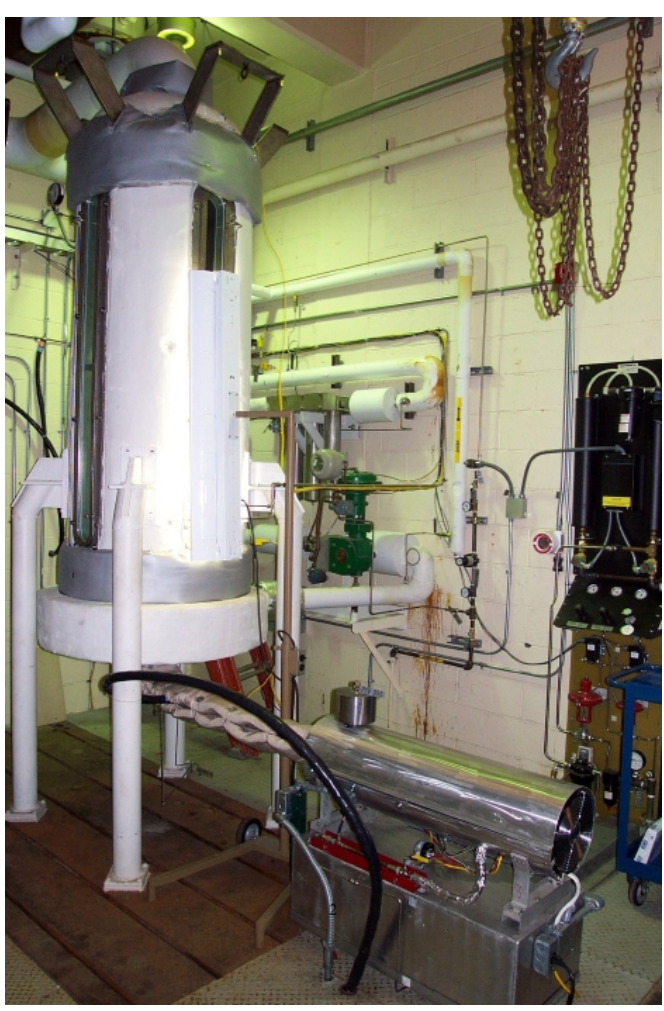

(b)

FIGURE 1: The Particulate Aerosol Laboratory: (a)sketch and (b)photograph. Note that in (b), the burner is covered by a pressure housing. The gas (nitrogen or air) from the cold gas supply simulates the atmosphere, and the burner exhaust simulates aircraft engine exhaust.

\section{Introduction}

Although particulate emissions from aircraft engines were initially of concern because of the visible smoke $[1,2]$, recent research has focused on the health and environmental effects of ultrafine particulate emissions. Due to the negative health effects of ultrafine particles, the regulations on particles smaller than 2.5 microns have become increasingly stringent [3]; most particulates emitted by aircraft are smaller than 2.5 microns $[1,4]$.

A major environmental effect of aircraft particulate emissions is their effect on the the formation and properties of cirrus clouds in the troposphere; however, this effect is not well understood [5]. Several areas require further research, including the microphysical and chemical processes governing the evolution of aviation particulates. Previous work has sought to characterize aircraft engine emissions using combustion rigs, on-ground engine tests $[4,6-8]$, and measurements taken in the aircraft engine plumes at altitude [6]. The work described in this paper complements these efforts.

This paper describes measurements taken in the Particulate Aerosol Laboratory (PAL) at NASA Glenn Research Center. In this unique facility, a combustor capable of burning jet fuel exhausts into an altitude chamber capable of simulating temperature and pressure conditions up to $45,000 \mathrm{ft}$, allowing the particle evolution to be studied at altitude conditions. A scanning mobility particle sizer (SMPS) measures the particulate profile at the combustor exit and in the altitude chamber. The probe used to sample the exhaust plume in the altitude chamber can be placed at discrete axial positions that range from the exhaust nozzle exit to the top of the altitude chamber. This paper will present initial measurements of the particle size distribution taken from the combustor and measurements of the particle size distribution taken in the altitude chamber.

\section{Facilities and Instrumentation 2.1 Facility Description}

The Particulate Aerosol Laboratory (PAL) consists of a burner connected to an altitude chamber, as shown in Figure 1. The burner is capable of burning conventional jet fuels and alternative fuels such as Fischer-Tropsch. A 1.6-m long transition 
pipe connects the burner exit to the altitude chamber; the transition pipe terminates in a $1.27-\mathrm{cm}$ diameter nozzle that exhausts the combustion products into the altitude chamber. The altitude chamber can simulate standard day pressures and temperatures up to altitudes of $13,700 \mathrm{~m}$.

As shown in Figure 1a, the burner is composed of two parts: a combustion chamber and a mixing chamber. The upstream section of the combustion chamber is surrounded by the mixing chamber. The main combustion air enters the burner in the annular area between the combustion chamber and the combustion chamber casing. (A bulkhead prevents mixing between the main air in this annular area and the combustion products in the mixing chamber.) Flowing upstream, the main air enters the combustion zone through a $3.81-\mathrm{cm}$ diameter opening in the upstream end of the combustion chamber. Fuel and a small quantity of atomization air enter the combustion chamber through an air assist fuel injector. The combustion products enter the mixing chamber through a $0.635-\mathrm{cm}$ annular slot in the downstream end of the combustion chamber. The entire burner is surrounded by a housing, as shown in $1 \mathrm{~b}$. The burner pressure is one to two atmospheres.

After exiting the burner, the combustion products flow through a $2.43-\mathrm{cm}$ inner diameter transition pipe into the altitude chamber. An orifice in the transition pipe drops the pressure of the combustion products to near the pressure of the altitude chamber. Ports in the transition pipe upstream of the orifice allow combustion product samples to be drawn for gas and particulate analysis.

A cold gas supply (nitrogen or air) provides the working fluid for the altitude chamber. This working fluid simulates the atmosphere and allows the effects of mixing between the hot combustor exhaust and a cold atmosphere to be studied. Nitrogen was the working fluid for all measurements reported here.

The chamber diameter is $0.597-\mathrm{m}$, and the height of its cylindrical test section in 1.83-m. Four window ports, each 1.52$\mathrm{m}$ tall by $0.102-\mathrm{m}$ wide, are located $90^{\circ}$ apart from each other. The window ports can be fitted with windows, instrumentation plates, or blanks. When a window is installed, two panes of glass are used, and the space in between the panes is kept at vacuum; this prevents condensation on the windows and also provides good insulation. (When a blank or instrumentation plate is used, it is a single thickness of aluminum and does not provide good insulation.) For the measurements reported here, three ports contained windows and one port contained an instrumentation plate; Figure 1a shows the instrumentation plate that was used during these measurements.

\subsection{Instrumentation}

A TSI scanning mobility particle sizer (SMPS) system model 3936NL76 - consisting of a TSI model 3776 condensation particle counter (CPC), a TSI model 3080 electrostatic clas-

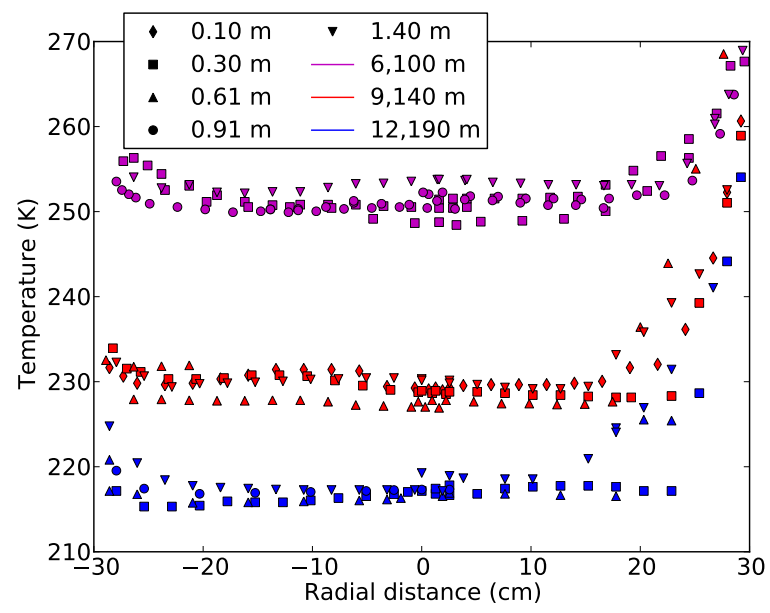

FIGURE 2: Baseline chamber temperature distribution with the burner off.

sifier, and a TSI model 3085 nano differential mobility analyzer - was used to measure the particle size distribution. The CPC was also used alone to measure the particle count.

A blunt-tipped sampling probe with a $0.32-\mathrm{cm}$ inner diameter was inserted into the transition pipe facing normal to the flow. This probe was used to sample the particle distribution at the burner exit. To minimize agglomeration and condensation in the sampling system, the combustion products were diluted with dry nitrogen slightly downstream of the probe tip.

A blunt-tipped sampling probe was also used to measure the particle count in the altitude chamber. The probe face was parallel to the primary flow direction except for the measurements at $0.18 \mathrm{~m}$ downstream of the nozzle exit at $12,190 \mathrm{~m}$ standard day conditions; in this single case, the probe face was approximately normal to the primary flow direction. This probe had a $0.4-\mathrm{cm}$ inner diameter and could be covered with heat tape to prevent ice formation inside the probe. It was connected to a translation stage that allowed it to be moved radially.

\subsection{Test Conditions}

Four burner conditions (see Table 1) and four altitude chamber conditions were studied. The altitude chamber conditions corresponded to standard day temperatures and pressures at 6,100 m; 9,140 m; and 12,190 m [9] as well hot day temperature and pressure conditions at 9,140 $\mathrm{m}$ [10] (see Table 2). The chamber Reynolds number indicates that the flow was turbulent for all cases. As Figure 2 shows, the baseline temperature in the altitude chamber (when no combustion products are added) is nearly uniform except in the thermal boundary layer. (Note a double-paned window is installed on the negative $r$ side of the altitude chamber, and an uninsulated instrumentation plate is in- 
TABLE 1: Burner conditions

\begin{tabular}{ccccccccccc}
\hline Condition & Fuel/Air & Total Mass & \multicolumn{4}{c}{$l_{M}$ at } \\
Number & Ratio & $\begin{array}{c}\text { Flow Rate } \\
\mathrm{kg} / \mathrm{min}\end{array}$ & $\begin{array}{c}6,100 \mathrm{~m} \\
\mathrm{~m}\end{array}$ & $\begin{array}{c}7,620 \mathrm{~m} \\
\mathrm{~m}\end{array}$ & $\begin{array}{c}9,140 \mathrm{~m} \\
\mathrm{~m}\end{array}$ & $\begin{array}{c}12,190 \mathrm{~m} \\
\mathrm{~m}\end{array}$ & $\begin{array}{c}6,100 \mathrm{~m} \\
\mathrm{~cm}\end{array}$ & $\begin{array}{c}7,620 \mathrm{~m} \\
\mathrm{~cm}\end{array}$ & $\begin{array}{c}9,140 \mathrm{~m} \\
\mathrm{~cm}\end{array}$ & $\begin{array}{c}12,190 \mathrm{~m} \\
\mathrm{~cm}\end{array}$ \\
\hline 1 & 0.045 & 0.166 & 2.16 & 2.82 & 3.02 & 4.55 & 3.0 & 3.1 & 2.9 & 2.8 \\
2 & 0.032 & 0.230 & 2.98 & 3.88 & 4.18 & 6.28 & 3.0 & 3.1 & 2.9 & 2.8 \\
3 & 0.017 & 0.342 & 4.50 & 5.88 & 6.28 & 9.43 & 3.1 & 3.2 & 3.0 & 2.9 \\
4 & 0.007 & 0.336 & 4.99 & 6.65 & 6.75 & 9.95 & 3.5 & 3.6 & 3.4 & 3.3 \\
\hline
\end{tabular}

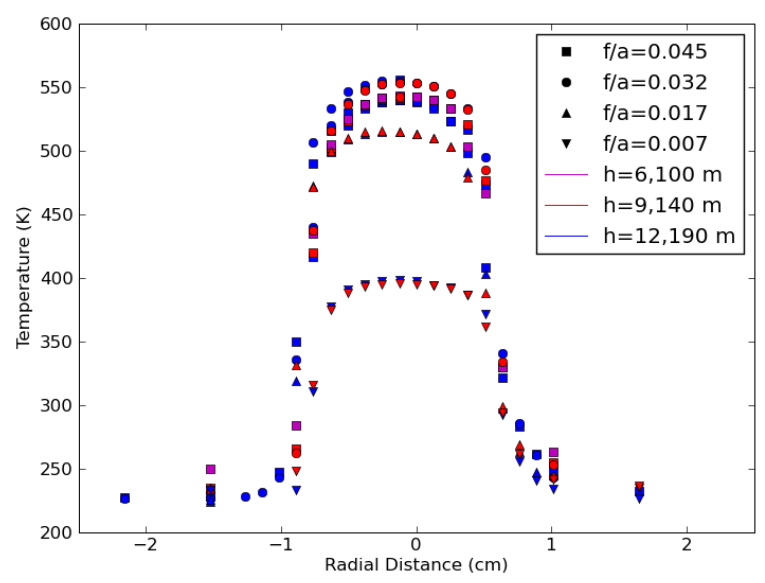

FIGURE 3: Combustion product temperature as combustion products exit the nozzle into the altitude chamber at $\mathrm{x}=0$. For all cases the temperature rapidly returned to the baseline temperature as the radial distance $r$ increased, so only the region near the nozzle exit is shown.

stalled at the positive $r$ side of the instrumentation chamber; this accounts for the asymmetry in the temperature distribution near the chamber walls.)

Figure 3 shows the temperature distribution at the nozzle exit. Note that this temperature distribution does not change significantly with altitude, indicating that the section of the transition pipe that enters the bottom of the altitude chamber is wellinsulated.

\section{Facility Temperature Distribution}

Because the particle evolution depends strongly on temperature, the temperature distribution in the altitude chamber was characterized; the temperature distribution depends on the con- ditions at the nozzle exit, the conditions in the altitude chamber, and the type of flow field that is established. From several nozzle diameters downstream of the nozzle exit to the axial location where the effects of the altitude chamber walls become important, the flow field in the PAL should act as either a buoyant jet or a momentum-dominated jet. The relative effects of jet exit momentum and buoyancy are usually expressed in terms of the Richardson number, $R$, or the ratio of the axial distance from the nozzle exit, $x$, to the Morton length scale, $l_{M}[11,12]$. These are defined in terms of the jet volume flux, $Q$, the jet momentum flux, $J$, and the jet buoyancy flux, $B$, as:

$$
\begin{aligned}
R & =\frac{Q\left(B / \rho_{\infty}\right)^{\frac{1}{2}}}{\left(J / \rho_{\infty}\right)^{\frac{5}{4}}} \\
l_{M} & =\frac{\left(J_{0} / \rho_{\infty}\right)^{\frac{3}{4}}}{\left(B_{0} / \rho_{\infty}\right)^{\frac{1}{2}}}
\end{aligned}
$$

where

$$
\begin{aligned}
Q & =\int_{0}^{\infty} \bar{u}(x, r) 2 \pi r \mathrm{~d} r, \\
B & =\int_{0}^{\infty} g \overline{\Delta \rho u}(x, r) 2 \pi r \mathrm{~d} r, \\
J & =\int_{0}^{\infty} \overline{\rho u^{2}}(x, r) 2 \pi r \mathrm{~d} r,
\end{aligned}
$$

$u$ is the axial velocity, $\rho$ is the density, and the subscripts 0 and $\infty$ refer to conditions at the jet exit and in the altitude chamber, respectively. In the jet-like limit, $R$ and $x / l_{M}$ are small; in the plume-like limit, $R$ approaches 1 and $x / l_{M}$ is large. Papanicolaou and List [12] have shown that $R \propto x$ in the jet-like limit and $R$ is constant in the plume-like limit. They have also shown that flows with $x / l_{M}<1$ exhibit jet-like scaling and flows with $x / l_{M}>5$ 
TABLE 2: Chamber conditions

\begin{tabular}{|c|c|c|c|c|c|c|c|}
\hline Altitude & Altitude & Day Type & Temperature & Pressure & $\left(\mathrm{kg} / \mathrm{m}^{3}\right)$ & $\begin{array}{l}\text { Chamber } \\
\text { Reynolds } \\
\text { Number }\end{array}$ & $\begin{array}{c}\text { Nominal } \\
\text { Chamber } \\
\text { Coflow } \\
\text { Velocity } \\
(\mathrm{m} / \mathrm{s})\end{array}$ \\
\hline 6,100 & 20,000 & Standard & 249 & 46.601 & 0.653 & 17,900 & 0.7 \\
\hline 7,620 & 25,000 & Hot & 259 & 37.650 & 0.490 & 18,700 & 1.0 \\
\hline 9,140 & 30,000 & Standard & 228 & 30.149 & 0.459 & 25,800 & 1.4 \\
\hline 12,190 & 40,000 & Standard & 217 & 18.823 & 0.303 & 32,100 & 2.5 \\
\hline
\end{tabular}

exhibit plume-like scaling.

For the measurements reported here, the axial locations of interest range from several nozzle diameters to $71 \mathrm{~cm}$ downstream of the nozzle exit. In this region, $R$ is small and $x / l_{M} \ll 1$ (see Table 1), so the effects of buoyancy should not be significant. A similar length scale analysis of the effects of the cold nitrogen coflow [13] shows that the coflow effects should also be small. Therefore, the flow field is momentum-dominated and should follow nonbuoyant jet scaling laws.

For momentum-dominated jets, it can be shown $[14,15]$ that a conserved scalar, such as the normalized temperature difference, $\theta \equiv \frac{T-T_{\infty}}{T_{0}-T_{\infty}}$, is inversely proportional to the normalized distance from the virtual origin, $\left(x+x_{E}\right) / d^{*}$, where $x$ is the distance from the jet exit, $x_{E}$ is the distance from the virtual origin to the jet exit, and $d^{*}=d_{0} \sqrt{\frac{\rho_{0}}{\rho_{\infty}}}$. Diez \& Dahm [11] ${ }^{1}$ show that for a momentum-dominated or buoyant jet the distance $x_{E}$ that the virtual origin is upstream of the nozzle exit is given by:

$$
x_{E}=l_{M}\left\{\left(\frac{I_{1}^{2}}{I_{2}^{5 / 2} c_{\delta} c_{u, j}^{3}}\right)\left[\frac{\left(J_{0} / \rho_{\infty}\right)^{5 / 2}}{\left(m_{0} / \rho_{\infty}\right)^{2}\left(B_{0} / \rho_{\infty}\right)}\right]\right\}^{-\frac{1}{2}},
$$

where

$$
\begin{aligned}
I_{1} & =0.262, \\
I_{2} & =0.131, \quad \\
c_{\delta} & =0.36, \quad \text { and } \\
c_{u, j} & =7.2
\end{aligned}
$$

In other words, $\theta=c_{\theta}\left(\frac{x+x_{E}}{d^{*}}\right)^{-1}$, where $c_{\theta}$ is approximately 5.4

\footnotetext{
${ }^{1}$ The formula given here does not match the one given by equations 42 and 47 in [11]. There seem to be several typographical errors in [11], with the missing exponent of $-1 / 2$ in equation 47 being the most important. The missing exponent can be found by following the derivation described in the text of [11] and substituting equation 46 into equation 44 .
}

NASA/TM-2012-217257
[16]. Furthermore, momentum-dominated jets are self-similar, so a conserved scalar normalized by its centerline value is a function of the radius normalized by the jet width, $\delta$; that is, $\theta / \theta_{C L}=f(r / \delta)$. For both momentum-dominated and buoyant jets, $\delta$ is proportional to axial distance from the virtual origin; therefore, $\theta / \theta_{C L}=f^{\prime}\left(\frac{r}{x+x_{E}}\right)$. Figures $4 \mathrm{a}$ and $4 \mathrm{~b}$ support this scaling: Figure $4 \mathrm{a}$ is consistent with $\theta / \theta_{0}=5.4\left(\frac{x+x_{E}}{d^{*}}\right)^{-1}$ scaling until the effect of the altitude chamber wall becomes important at $\frac{x+x_{E}}{d^{*}} \approx 130$. Figure $4 \mathrm{~b}$ shows that $\theta / \theta_{C L}$ is a function of $r /\left(x+x_{E}\right)$ for $r /\left(x+x_{E}\right)$ values that are sufficiently far from the chamber walls. (When interpreting Figure $4 b$, note that the temperature increase due to the chamber walls is more important on the poorly-insulated instrument plate side of the chamber $(+r)$ than on the relatively well-insulated window side $(-r)$ and that as the axial distance increases the $r /\left(x+x_{E}\right)$ value at which the wall effects become important decreases.) Also shown in Figure $4 \mathrm{~b}$ are a curve fit to the data, the normalized concentration profile, $\zeta / \zeta_{C L}$, used by Diez \& Dahm [11], and the normalized velocity profile, $u / u_{C L}$, used by Hussein et al. [17]. The curve fit used to model the current data and the profiles used by the Diez \& Dahm and Hussein et al are of the form $\xi=e^{-\alpha\left(\frac{r}{x+x e}\right)^{2}}$, where $\xi$ is $\theta / \theta_{C L}, \zeta / \zeta_{C L}$, or $u / u_{C L}$. The width parameter $\alpha$ of the $\theta / \theta_{C L}$ is between the $\alpha$ values for $\zeta / \zeta_{C L}$ and $u / u_{C L}$, further indicating that the jet scaling is appropriate for the normalized temperature difference $\theta$.

\section{Initial Particle Evolution Measurements}

Particle measurements were taken both in the transition pipe (see Figure 1) and in the altitude chamber for burner condition 1 from Table 1 and at all chamber conditions listed in Table 2. For the particle measurements made in the transition pipe, the sample was diluted with nitrogen with a dilution ration of 1.91 to prevent condensation and agglomeration in the sampling line; the sample 

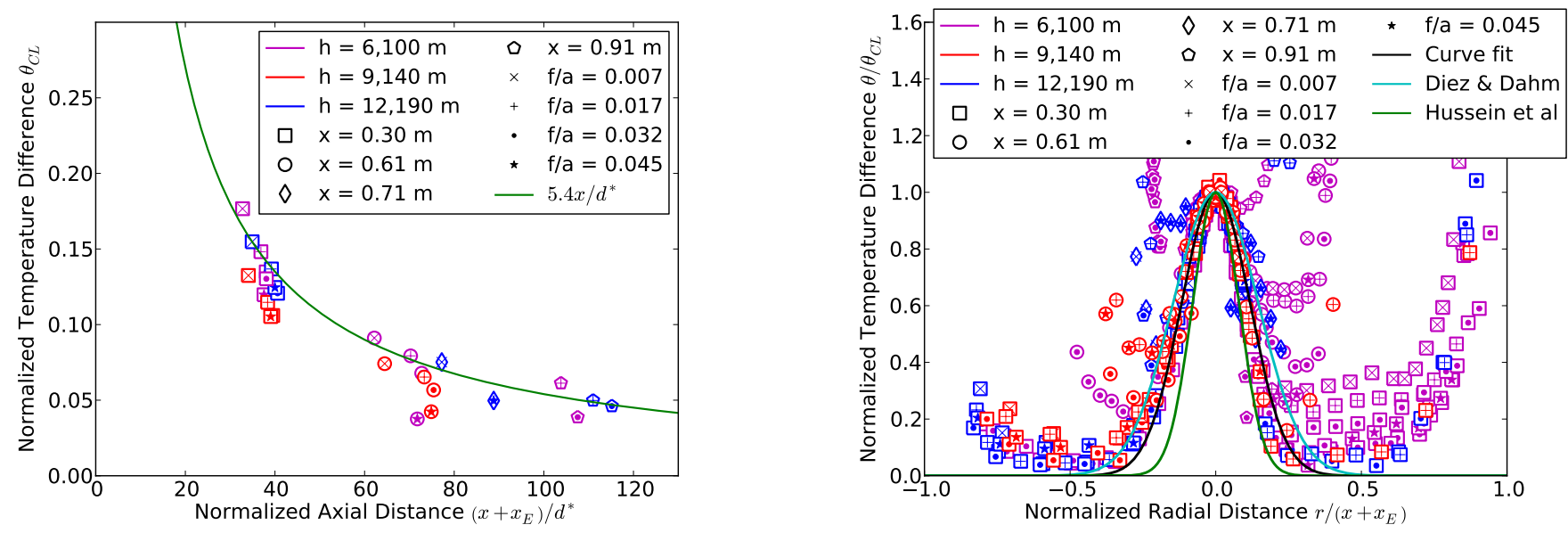

FIGURE 4: (a)Normalized jet centerline temperature $\theta_{C L}$ as a function of normalized axial distance $\left(x+x_{E}\right) / d^{*}$ and (b) the normalized temperature distributions as a function of the normalized radial distance. The symbol color indicates the altitude conditions, the 'outer' symbol indicates the axial position, and the 'inner' symbol indicates the fuel-air ratio. Note that the effects of the chamber wall are important when $\left(x+x_{E}\right) / d^{*}>130$.

was not diluted for measurements made in the altitude chamber.

\subsection{Burner Measurements}

A representative particle number distribution in the transition pipe is shown in Figure 5. Integrating the particle number distribution gives a total number concentration of $1.2 \times 10^{7}$ particles per standard cubic centimeter, where standard pressure and temperature are defined as $101.325 \mathrm{kPa}$ and $298.15 \mathrm{~K}$, respectively.

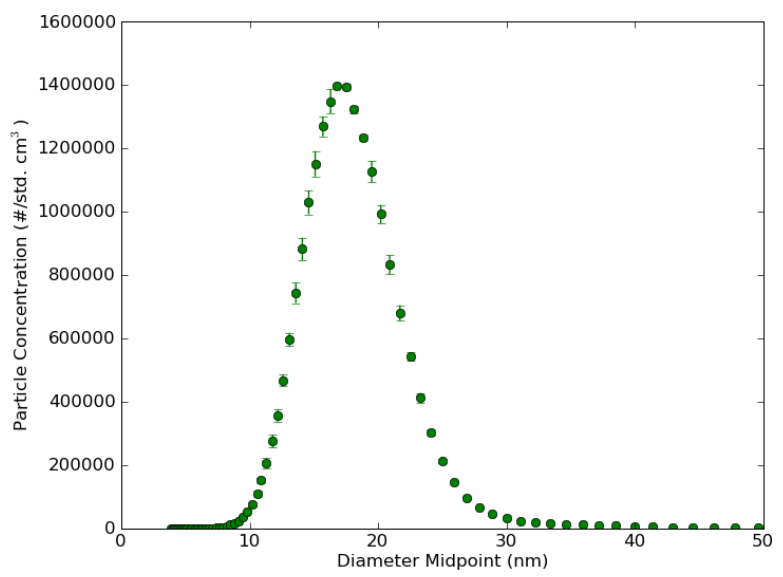

FIGURE 5: Particle number distribution in the transition pipe for burner condition $1(\mathrm{f} / \mathrm{a}=0.045)$

NASA/TM-2012-217257
Note, however, that the particle measurements taken in the chamber suggest that the combustor particle output is not steady (see the next section). The variation of combustor particle output with time is being measured, and for future tests, two particle measurement systems will be used so that the particle distributions in the transition pipe and in the altitude chamber can be measured simultaneously. 


\subsection{Initial Measurements in the Altitude Chamber}

Initially, attempts were made to take particle evolution measurements in the altitude chamber with standard day pressure and temperature conditions corresponding to 9,140 m. Unfortunately, at these conditions, the water vapor in the jet condenses, and in some cases freezes, in the sampling probe. Therefore, heat tape was wrapped around the sampling probe and the altitude chamber conditions were changed to the considerably warmer hot day conditions at 7,620 m. For these chamber conditions and burner condition 1, Figure 6 shows the particle number concentration as a function of radial distance at axial distance 0.30 and $0.51 \mathrm{~m}$ downstream of the jet exit. (Note that in Figure 6 and in all other figures showing the particle number concentration, the number concentration is given in particles per actual cubic centimeter at the particle counter, not in particles per standard cubic centimeter. At the particle counter, the temperature is approximately standard temperature but the pressure is the altitude chamber pressure.)

After successfully measuring the particle number concentration with a heat tape-wrapped probe at hot day conditions corresponding to 7,620 m, initial particle number concentrations were measured at standard day conditions corresponding to $6,100 \mathrm{~m}$, $9,140 \mathrm{~m}$, and $12,190 \mathrm{~m}$, as shown in Figures 7 and 8 . In all cases, it was possible to measure the particle number concentration with the heat tape turned on. However, when the heat tape was turned off, it was not possible to measure the number concentration near the jet centerline at $6,100 \mathrm{~m}$ and 9,140 $\mathrm{m}$ because the number concentration was above the maximum concentration that the CPC could measure.

(Note that in several of the plots, there appear to be two separate particle curves. This is most apparent in the measurements taken with the heat tape on at 6,100 m conditions in Figure 7a. In all cases, the measurements were taken at different times, and the difference between the measurements appear to be a real change in the particle concentration, not a lack of precision in the CPC. For example, the "upper" curve in 7a was taken earlier in the day than the "lower" curve. The change in particle concentration could be caused by either a change in the chamber conditions or a change in the particle output from the combustor. Because the chamber conditions were constantly monitored to ensure the temperature and pressure remained as constant as possible, it seems to be more likely that a change in particle output from the combustor was responsible for the change in the chamber particle concentration. In the future, the combustor particle size distribution will be monitored continuously; for the measurements reported here, the same CPC was used for the combustor and the chamber particle measurements and these measurements could not be taken simultaneously.)

In addition, icing continued to be a problem. It was possible to prevent ice from forming in the sampling probe and at the sampling probe tip by avoiding sudden changes in the radial location of the probe and by briefly turning on the heat tape to melt the ice if it began to form. However, it is unclear how many of the particles measured when the heat tape was turned off were present in the plume and how many were formed in the probe.

Unfortunately, it is also unclear that measurements taken when the heat tape was turned on accurately reflect the number of particles in the jet plume. For the heated-probe measurements taken at 12,190 m conditions, the peak particle concentration occurs off the centerline, which is an unexpected result. However, for the heated-probe measurements taken at all other chamber conditions, the peak particle concentration occurs on the centerline, as expected. Research groups measuring the particulate emissions of jet engines on the ground have also noticed unexpected and as yet unexplained effects when using heated probes ${ }^{2}$, so it appears that using a heated probe is not an ideal solution.

Figure 9 shows the normalized particle number concentration profiles, $\zeta / \zeta_{\max }$ vs. $r /\left(x+x_{E}\right)$. The profiles at chamber conditions corresponding to altitudes of $6,100 \mathrm{~m}$ and $9,140 \mathrm{~m}$ measured with a heated probe were consistent with the normalized temperature profiles, $\theta / \theta_{C L}$. Both profiles at a chamber condition corresponding to $7,620 \mathrm{~m}$, also taken with a heated probe, collapsed onto each other but the profiles were narrower than the normalized temperature profile. The profiles taken with an unheated probe at a chamber condition corresponding to $12,190 \mathrm{~m}$ are wider than the normalized temperature profile, and the profiles taken with a heated probe at the same chamber conditions have a maximum value off the centerline. Both of the heatedand unheated-probe $12,190 \mathrm{~m}$ profiles are very different in shape than the normalized temperature profiles.

Figure 10 shows the maximum concentration at each axial location and chamber condition as a function of the normalized downstream distance, $x / d^{*}$. If the particle number concentration is a conserved scalar, the maximum concentration will decrease with axial distance from the nozzle exit. However, as the temperature in the jet cools, volatile particles will form; if a large enough number of volatile particles is formed, the particle number concentration will increase with axial distance. In addition, the heated probe may revaporize some or all of the volatile particles formed in the jet. (Because all particle measurements are done at room temperature, some particles may also revaporize in the sampling line between the altitude chamber and the condensation particle counter for both the heated and unheated probe cases.)

The results from Figure 10 are inconclusive. At the warmest chamber temperature — which occurs at the 7,620 m hot day conditions - the maximum particle concentration decreases with axial distance when the probe is heated. At the coldest chamber temperature, - which occurs at the $12,190 \mathrm{~m}$ standard day conditions - the particle concentration increases with axial distance when the probe is heated. So far, because more volatile particles will form at the cold 12,190 m standard day conditions 


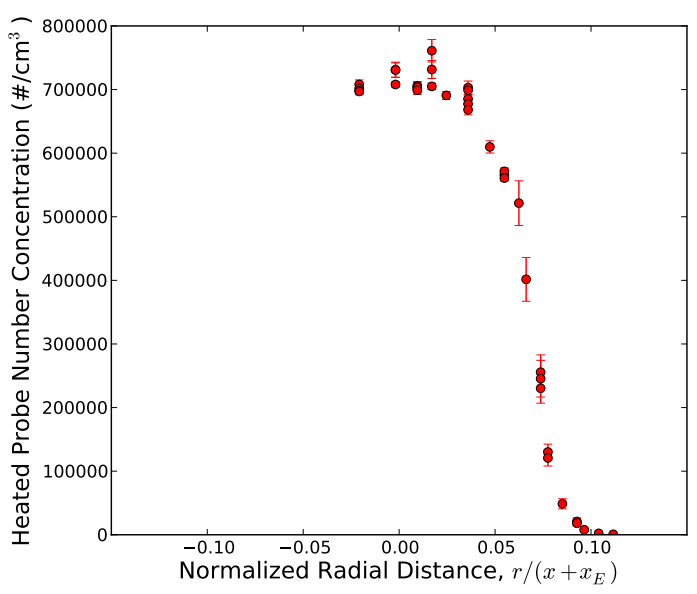

(a)

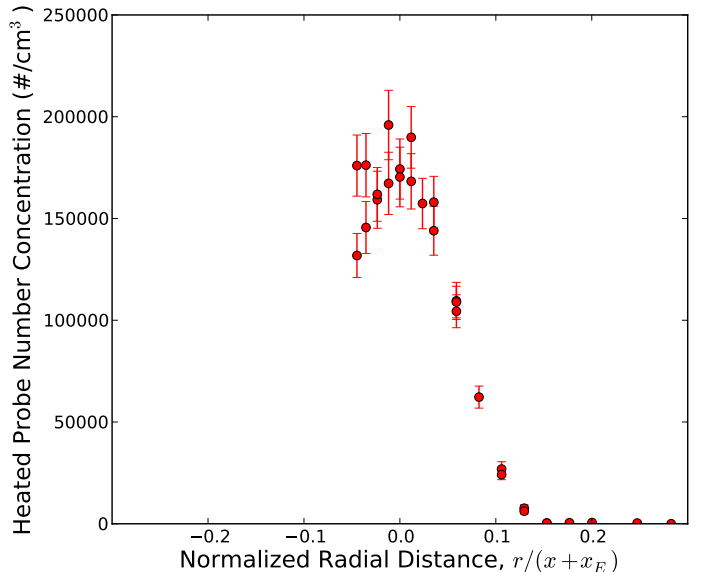

(b)

FIGURE 6: Particle count at 7,620 $\mathrm{m}$ hot day conditions and at (a) $x=0.30 \mathrm{~m}$ and (b) $x=0.51 \mathrm{~m}$ downstream of the nozzle exit. Heat tape is wrapped around the particle probe for both cases.
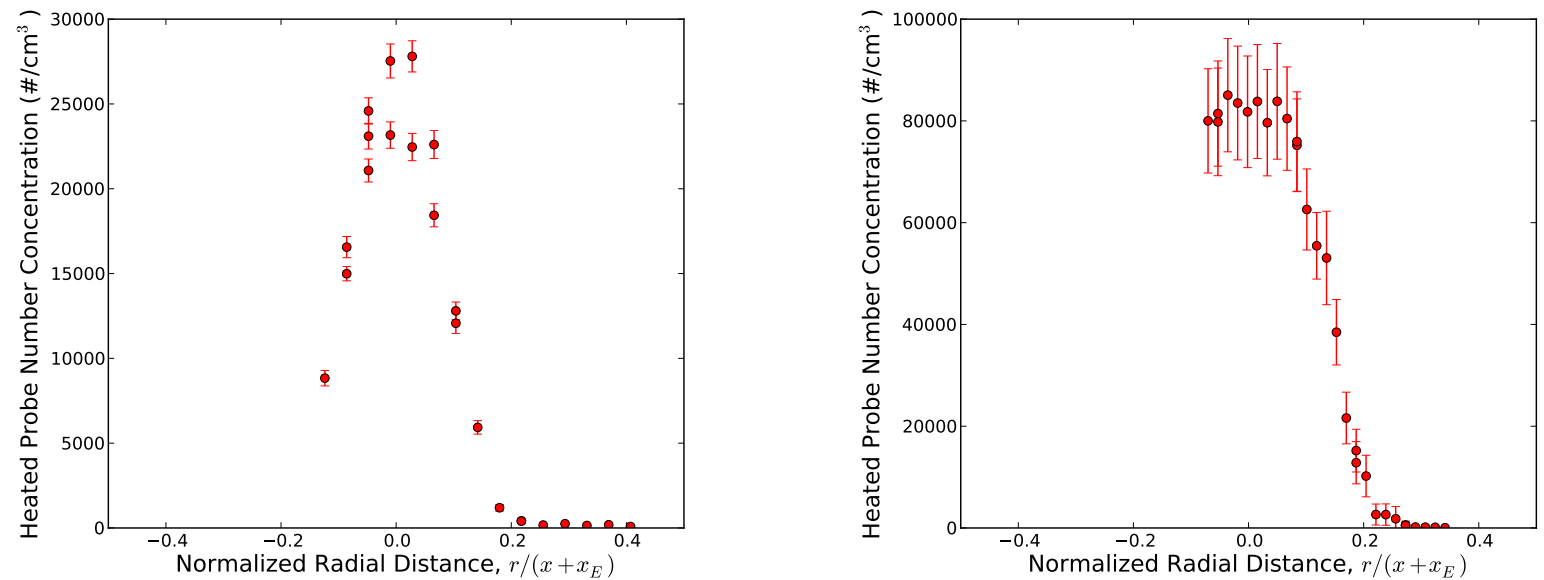

FIGURE 7: Particle number as a function of radial location at (a) $6,100 \mathrm{~m}$ conditions and $x=0.30 \mathrm{~m}$ and (b) $9,140 \mathrm{~m}$ conditions and $x=0.71 \mathrm{~m}$. Red symbols indicate that the heat tape wrapped around the particle probe was turned on, and blue symbols indicate that it was turned off.

than at the much warmer 7,620 m hot day conditions, this could be consistent with volatile particles forming in the jet and then revaporizing in the heated probe. However, unheated probe measurements at the $12,190 \mathrm{~m}$ standard day conditions show particle number concentration decreasing with increasing axial distance; although this could be consistent with particles revaporizing in the sampling line, it is inconsistent with the heated probe measurements.

When particulate emissions measurements are taken on the ground or in a test cell, the particulate sample is diluted at the probe tip to prevent condensation and to freeze the particulate chemistry. In this study, the altitude chamber particulate measurements were not diluted because the mixing in the jet dilutes the combustion products by a factor of between five and ten to one, depending on axial location. However, because the ambient temperature in the altitude chamber is much colder than the temperature in the jet - especially on the jet centerline and at the lower axial locations - more dilution may be necessary. For 

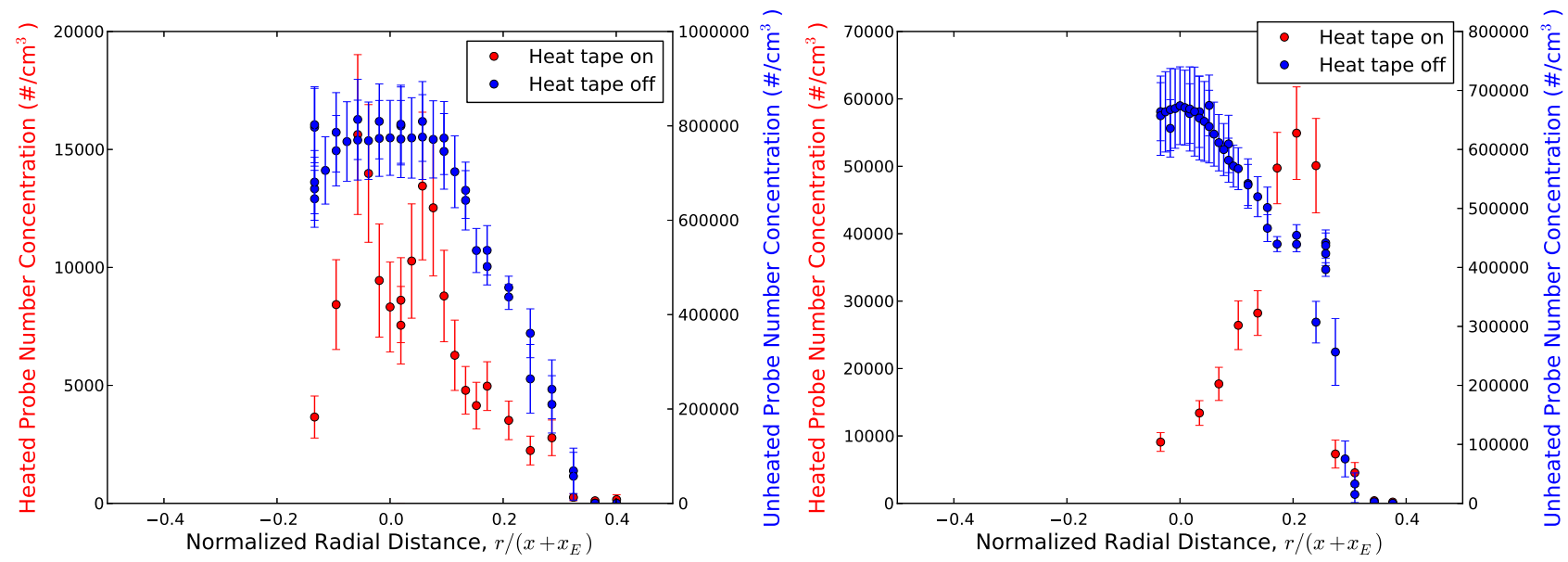

FIGURE 8: Particle concentration with and without heat tape at $12,190 \mathrm{~m}$ standard day conditions at (a) $0.18 \mathrm{~m}$ and (b) $0.71 \mathrm{~m}$ downstream of the nozzle exit. Red symbols indicate that the heat tape wrapped around the probe was turned on, and blue symbols indicate that it was turned off.

future measurements, diluting the particulate sample so that the vapor pressure of water in the sample is below the saturation vapor pressure at the ambient chamber conditions could prevent condensation in the probe.

Before further particle measurements are made in the altitude chamber, it would be best to do a modeling study of the particle sampling system. This study could help determine the

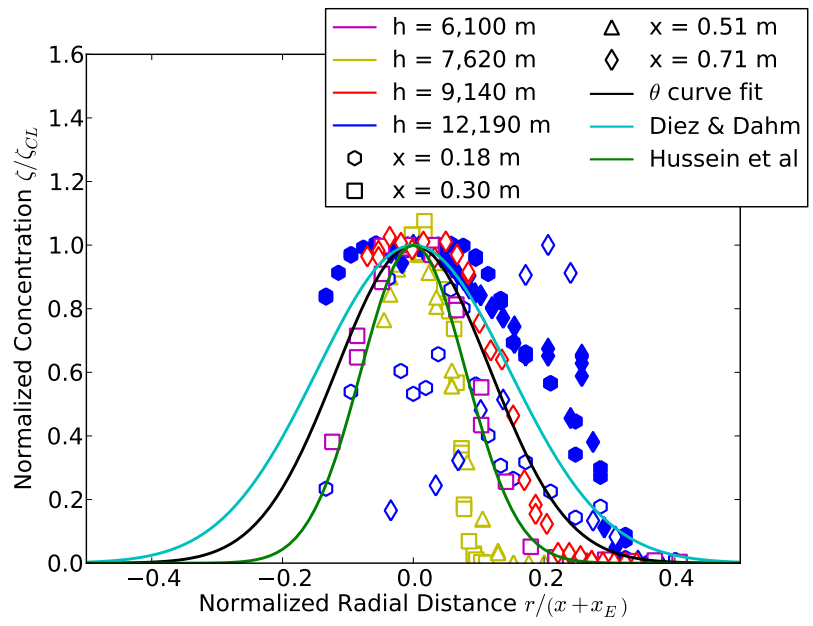

FIGURE 9: Normalized particle number distribution plotted with the curve fit for $\theta / \theta_{C L}$. Unfilled symbols are used for measurements taken when the heat tape was turned on, and filled symbols are used for measurements taken when the heat tape was turned off.

NASA/TM-2012-217257 degree of condensation in the unheated particle probe and the effects of heating the particle probe. It could also provide guidance for choosing a sampling flow rate and help determine if a larger diameter sampling probe or tip dilution could reduce the particle probe effects. 

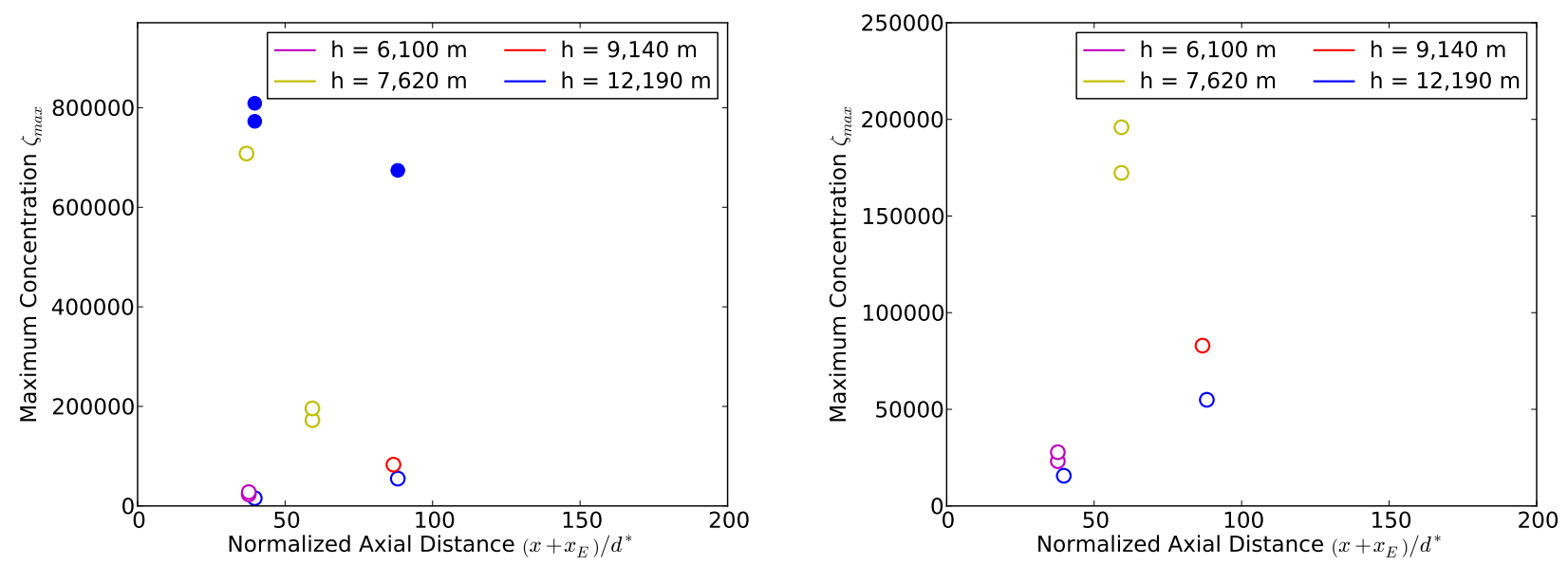

FIGURE 10: Maximum concentration as a function of the normalized axial distance. Unfilled symbols are used for measurements taken when the heat tape was turned on, and filled symbols are used for measurements taken when the heat tape was turned off.

\section{Conclusions}

Initial temperature and particle number concentration profiles were measured in the Particulate Aerosol Laboratory. This unique facility simulates engine exhaust at altitude by exhausting hot combustor exhaust into an altitude chamber. The small nitrogen coflow in the altitude chamber is kept at pressure and temperature conditions corresponding to aircraft cruising altitudes. Results from the normalized temperature distribution, $\theta$, show that the combustor exhaust flow field follows momentum-dominated jet scaling. Initial particle number concentration measurements were taken with a heated probe at four altitude chamber conditions and with an unheated probe at one altitude condition. Results show that whether the probe is heated or unheated affects the particulate measurements. Particle number concentrations measured with an unheated probe can be more than five times as great as those measured with a heated probe. In addition, the shape of the radial particle number concentration profile can be different when using an unheated probe than when using a heated probe. A modeling study of the particle sampling system should be done before further testing to determine the effects of probe heating and of condensation in the particle probe.

\section{REFERENCES}

[1] Blevins, L. G., 2003. Particulate matter emitted from aircraft engines. AIAA 2003-2764.

[2] SAE E-31 Technical Committee, 1997. Aircraft gas turbine smoke measurement. SAE ARP 1179.

[3] U.S. EPA, 2004. Air quality criteria for particulate matter (october 2004). EPA 600/P-99/002aF-bF, October.

[4] Anderson, B., Branham, H.-S., Hudgins, C., Plant, J., Ballenthin, J., Miller, T., Viggiano, A., Blake, D., Boudries, H., Canagaratna, M., Miake-Lye, R., Onasch, T., Wormhoudt, J., Worsnop, D., Brunke, K., Culler, S., Penko, P., Sanders, T., Han, H.-S., Lee, P., Pui, D., Thornhill, K., and Winstead, E., 2005. Experiment to characterize aircraft volatile aerosol and trace species emissions. NASA/TM-2005213783.

[5] Wuebbles, D.(workshop chair), 2006. Workshop on the impacts of aviation on climate change: A report of findings and recommendations. Report PARTNER-COE-2006-004SUMMARY, June.

[6] Schumann, U., Arnold, F., Busen, R., Curtius, J., Kärcher, B., Kiendler, A., Petzold, A., Schlager, H., Schröder, F., and Wohlfrom, K.-H., 2002. "Influence of fuel sulfur on the composition of aircraft exhaust plumes: The experiments SULFUR 1-7”. Journal of Geophysical Research, 107(D15).

[7] Bhargava, A., Beyersdorf, A.J.and Winstead, E., Thornhill, K., Liscinsky, D., Souza, J., Wey, C., Tacina, K., Timko, M., Yu, Z., Onasch, T., Miake-Lye, R., Corporan, E., Howard, R., DeWitt, J., and Klingshirn, C., 2008. The impact of alternative fuels on aircraft emissions. Presentation at 2008 aaar annual conference. 
[8] Wey, C., Anderson, B., Hudgins, C., Wey, C., Li-Jones, X., Winstead, E., Thornhill, L., Lobo, P., Hagen, D., and Whitefield, P. e. a., 2006. Aircraft particle emissions experiment. NASA/TM-2006-214382.

[9] , 1976. U.s. standard atmosphere, 1976. NOAA-S/T 761562.

[10] , 2007. Definition of commonly used day types (atmospheric ambient temperature characteristics versus pressure altitude). SAE/ARP210 2007-02.

[11] Diez, F. J., and Dahm, W. J., 2007. "Effects of heat release on turbulent shear flows. part 3. buoyancy effects due to heat release in jets and plumes.". Journal of Fluid Mechanics, 575, pp. 221-255.

[12] Papanicolaou, P. N., and List, E. J., 1988. "Investigations of round vertical turbulent buoyant jets". Journal of Fluid Mechanics, 195, pp. 341-391.

[13] Lee, J. H., and Chu, V. H., 2003. Turbulent Jets and Plumes: A Langrangian Approach, 1 ed. Kluwer Academic Publishers, Norwell, Massachusetts.

[14] Thring, M., and Newby, M., 1953. "Combustion length of enclosed turbulent jet flames". Proceedings of the 4th International Symposium on Combustion, pp. 789-796.

[15] Wygnanski, I., and Fiedler, H., 1969. "Some measurements in the self-preserving jet". Journal of Fluid Mechanics, 38 , pp. 577-612.

[16] Dahm, W. J., and Dimotakis, P. E., 1990. "Mixing at large schmidt number in the self-similar field of turbulent jets". Journal of Fluid Mechanics, 217, pp. 299-300.

[17] Hussein, J. H., Capp, S. P., and George, W. K., 1994. "Velocity measurements in a high-reynolds number, momentum-conserving, axisymmetric turbulent jet". Journal of Fluid Mechanics, 258, pp. 31-75. 


\begin{tabular}{|c|c|c|c|c|c|}
\hline \multicolumn{5}{|c|}{ REPORT DOCUMENTATION PAGE } & $\begin{array}{l}\text { Form Approved } \\
\text { OMB No. 0704-0188 }\end{array}$ \\
\hline \multicolumn{6}{|c|}{$\begin{array}{l}\text { The public reporting burden for this collection of information is estimated to average } 1 \text { hour per response, including the time for reviewing instructions, searching existing data sources, gathering and maintaining the } \\
\text { data needed, and completing and revivewing the collection of finformation. Send comments regarding this burden estimate or any other aspect of this collection of information, including suggestions for reducing this } \\
\text { burden, to Department of Defense, Washington Headquarters services, Directorate for Information Operations and Reports (0704-0188), } 1215 \text { Jefferson Davis Highway, Suite } 1204 \text {, Arlington, VA } 22202-4302 \text {. } \\
\text { Respondents should be aware that notwithstanding any other provision of law, no person shall be subject to any penalty for failing to comply with a collection of information if it does not display a currently valid OMB } \\
\text { control number. } \\
\text { PLEASE DO NOT RETURN YOUR FORM TO THE ABOVE ADDRESS. }\end{array}$} \\
\hline \multicolumn{2}{|c|}{$\begin{array}{l}\text { 1. REPORT DATE (DD-MM-YYYY) } \\
01-01-2012\end{array}$} & \multicolumn{3}{|c|}{$\begin{array}{l}\text { 2. REPORT TYPE } \\
\text { Technical Memorandum }\end{array}$} & 3. DATES COVERED (From - To) \\
\hline \multirow{3}{*}{\multicolumn{5}{|c|}{$\begin{array}{l}\text { 4. TITLE AND SUBTITLE } \\
\text { Evolution of Combustion-Generated Particles at Tropospheric Conditions }\end{array}$}} & 5a. CONTRACT NUMBER \\
\hline & & & & & 5b. GRANT NUMBER \\
\hline & & & & & 5c. PROGRAM ELEMENT NUMBER \\
\hline \multirow{3}{*}{\multicolumn{5}{|c|}{$\begin{array}{l}\text { 6. AUTHOR(S) } \\
\text { Tacina, Kathleen, M.; Heath, Christopher, M. }\end{array}$}} & 5d. PROJECT NUMBER \\
\hline & & & & & 5e. TASK NUMBER \\
\hline & & & & & $\begin{array}{l}\text { 5f. WORK UNIT NUMBER } \\
\text { WBS 561581.02.08.03.16.02 }\end{array}$ \\
\hline \multicolumn{5}{|c|}{$\begin{array}{l}\text { 7. PERFORMING ORGANIZATION NAME(S) AND ADDRESS(ES) } \\
\text { National Aeronautics and Space Administration } \\
\text { John H. Glenn Research Center at Lewis Field } \\
\text { Cleveland, Ohio 44135-3191 }\end{array}$} & $\begin{array}{l}\text { 8. PERFORMING ORGANIZATION } \\
\text { REPORT NUMBER } \\
\text { E-18012 }\end{array}$ \\
\hline \multirow{2}{*}{\multicolumn{5}{|c|}{$\begin{array}{l}\text { 9. SPONSORING/MONITORING AGENCY NAME(S) AND ADDRESS(ES) } \\
\text { National Aeronautics and Space Administration } \\
\text { Washington, DC 20546-0001 }\end{array}$}} & $\begin{array}{l}\text { 10. SPONSORING/MONITOR'S } \\
\text { ACRONYM(S) } \\
\text { NASA }\end{array}$ \\
\hline & & & & & $\begin{array}{l}\text { 11. SPONSORING/MONITORING } \\
\text { REPORT NUMBER } \\
\text { NASA/TM-2012-217257 }\end{array}$ \\
\hline \multicolumn{6}{|c|}{$\begin{array}{l}\text { 12. DISTRIBUTION/AVAILABILITY STATEMENT } \\
\text { Unclassified-Unlimited } \\
\text { Subject Categories: } 07 \text { and } 45 \\
\text { Available electronically at http://www.sti.nasa.gov } \\
\text { This publication is available from the NASA Center for AeroSpace Information, 443-757-5802 }\end{array}$} \\
\hline \multicolumn{6}{|c|}{ 13. SUPPLEMENTARY NOTES } \\
\hline \multicolumn{6}{|c|}{$\begin{array}{l}\text { 14. ABSTRACT } \\
\text { This paper describes particle evolution measurements taken in the Particulate Aerosol Laboratory (PAL). The PAL consists of a burner } \\
\text { capable of burning jet fuel that exhausts into an altitude chamber that can simulate temperature and pressure conditions up to } 13,700 \text { m. } \\
\text { After presenting results from initial temperature distributions inside the chamber, particle count data measured in the altitude chamber are } \\
\text { shown. Initial particle count data show that the sampling system can have a significant effect on the measured particle distribution: both the } \\
\text { value of particle number concentration and the shape of the radial distribution of the particle number concentration depend on whether the } \\
\text { measurement probe is heated or unheated. }\end{array}$} \\
\hline \multicolumn{6}{|c|}{$\begin{array}{l}\text { 15. SUBJECT TERMS } \\
\text { Combustion; Particulates; Emissions; Particles; Aerosol }\end{array}$} \\
\hline \multicolumn{3}{|c|}{ 16. SECURITY CLASSIFICATION OF: } & $\begin{array}{l}\text { 17. LIMITATION OF } \\
\text { ABSTRACT }\end{array}$ & $\begin{array}{l}\text { 18. NUMBER } \\
\text { OF }\end{array}$ & $\begin{array}{l}\text { 19a. NAME OF RESPONSIBLE PERSON } \\
\text { STI Help Desk (email:help@sti.nasa.gov) }\end{array}$ \\
\hline $\begin{array}{l}\text { a. REPORT } \\
\text { U }\end{array}$ & $\begin{array}{l}\text { b. ABSTRACT } \\
\text { U }\end{array}$ & \begin{tabular}{|l|} 
c. THIS \\
PAGE \\
U \\
\end{tabular} & UU & $\begin{array}{l}\text { PAGES } \\
17\end{array}$ & $\begin{array}{l}\text { 19b. TELEPHONE NUMBER (include area code) } \\
443-757-5802\end{array}$ \\
\hline
\end{tabular}



